$\xi_{p}$

\title{
Hand Dominance Effect During right (Accelerator) Throttle Gripping in Riding Simulation
}

\author{
Nursalbiah Nasir ${ }^{*}$, Asyraf Hakimi Azmi ${ }^{2}$, Helmi Rashid ${ }^{3}$ \\ ${ }^{123}$ Faculty of Mechanical Engineering, Universiti Teknologi MARA, 40450 Shah Alam, Malaysia \\ *Corresponding author E-mail: nursalbiah@salam.uitm.edu.my
}

\begin{abstract}
This study investigated the difference in muscle activation of the muscles in right handed (RH) and left handed (LH) participants during riding of motorcycle simulator. Five participants ( $3 \mathrm{RH}$ and $2 \mathrm{LH}$ ) with average age of $24.2 \pm 0.447$ years old were recruited and they were requested to ride the simulator for certain period of times for three days. Two surface electromyogram (sEMG) electrodes were attached to right flexor carpi radialis (RFCR) and left flexor carpi radialis (LFCR) of the participants forearm. Electromyography (EMG) of flexor carpi radialis (FCR) are measured at both hands during the task. The results showed that muscle activation during first 5 minutes of riding task in day 1 of experiment (percentage of maximum voluntary contraction, \%MVC) for RFCR in LH (non-dominant) participants was $97.4 \%$ and $87.7 \%$ in RH (dominant) participants. Therefore, this result indicates that non-dominant person needs to activate more muscle than RH person during control the accelerator throttle while riding.
\end{abstract}

Keywords: Electromyography; Muscle activation; Hand dominance; Grip

\section{Introduction}

In Malaysia the percentage of using motorcycle is higher than developed countries such as Japan and Europe. Due to this fact, Malaysia has the highest road fatality risk (per 100,000 population) among the Association of Southeast Asian Nations (ASEAN) countries and more than $50 \%$ of the road accident fatalities involve motorcyclists [1]. Although many studies and investigations are done to reduce accidents, only small considerations of ergonomics were looked into of such cause of motorcycle accidents [2].

Despite having to study human behaviour in real condition, simulator is a better option to be used for investigation due to the $a b$ sence of real hazardous conditions from the real road [3]. Motorcycle simulators are invented to simulate actual experience of riding motorcycle in a controlled laboratory environment with the capability to compute the dynamic behaviour of the motorcyclist [3]. Nonetheless, majority of studies of simulators are conducted using the car or aircraft simulators than motorcycle simulator.

Muscle fatigue is identified as a decline in muscle activity when generating force. According to [4], muscle becomes fatigue when human feels pain while doing tasks in certain period of time. Some studies had confirmed on fatigue effect in prolong condition such as prolonged sitting in train ride [5], prolong standing [6,7] and prolong riding [8]. Rashid [8] found that muscle fatigue experienced by motorcyclists during prolonged riding could be one of probable cause of road fatalities.

In motorcycle ride, handling of the handle bar is very important because it controls the motorcycle speed and balance. The handle bar consists of the accelerator (right throttle), speedometer and certain models would also have hand clutch (left throttle). During prolong and monotonous riding, the hand position and throttle grip remains at the same posture for long time. Eventually, the muscles will become fatigue and causes numbness and pain. The pain would distract human focus and control of the vehicle which lead to accidents.

As $90 \%$ of world populations are right handed people right handed person including motorcycle. For left handed people, they would have to adapt themselves to use the products and systems $[9,10]$. It is not clearly known how well their performance in adapting when doing task using non-dominant hand.

Due to limited studies on hand dominance effect on performing task particularly in motorcycle riding this study is conducted. The objective of this study is to investigate the difference in various muscle activation of the right handed (RH) and left handed (LH) participant by using surface electromyogram (sEMG) while riding the Postura MotergoTM motorcycle simulator.

\section{Method}

\subsection{Participants}

5 young male university students consist of $2 \mathrm{LH}$ and $3 \mathrm{RH}$ participants with average age of $24.2 \pm 0.45$ years old. The participants did not have any diseases related to the hands, fractures, or past histories of diseases or fractures, and they were normally healthy persons without neurologic disorders. Their handedness preference was confirmed by modified Edinburgh Handedness Inventory [11]. Prior to the experiment, all procedures were explained to the participants in detail. This study was approved by the Research Ethics Committee of the Research Management Institute (RMI), MARA University of Technology, Malaysia (600RMI (5/1/6)) and written consent was obtained from all participants. 


\subsection{Experimental Set Up}

All participants were requested to ride the Postura Motorgo ${ }^{\mathrm{TM}}$ motor simulator for three days respectively. The riding posture is the same just like the real application for riding in real world. Participants would grip both throttles; right throttle for acceleration and left for stabilize the handle bar. A big white screen was located in front of the simulator to display simulation track (Fig.1) This experiment was conducted in Motorcycle Engineering Technology Laboratory (METAL) of the Faculty of Mechanical Engineering,

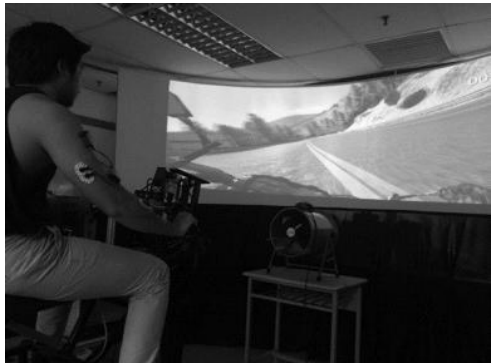

Fig. 1: Riding posture and experimental setup of the Postura Motorgo ${ }^{\mathrm{TM}}$.

\subsection{Procedure}

The experiment was conducted at ambient temperature of about $26^{\circ} \mathrm{C}$. EMG sensors were located on measured muscles at both forearm; right flexor carpi radialis (RFCR) and left flexor carpi radialis (LFCR). The maximal isometric voluntary contraction (MVC) was obtained before the experimental task. Next, they were required to sit on the simulator. A five minute practice time were given for participants to familiarize with the simulation track. Next, the participant must ride the simulator for 15 minutes in day 1 (Fig. 2 (a)), 30 minutes in day 2 (Fig. 2(b)) and for 45 minutes in day 3 (Fig. 2(c)).
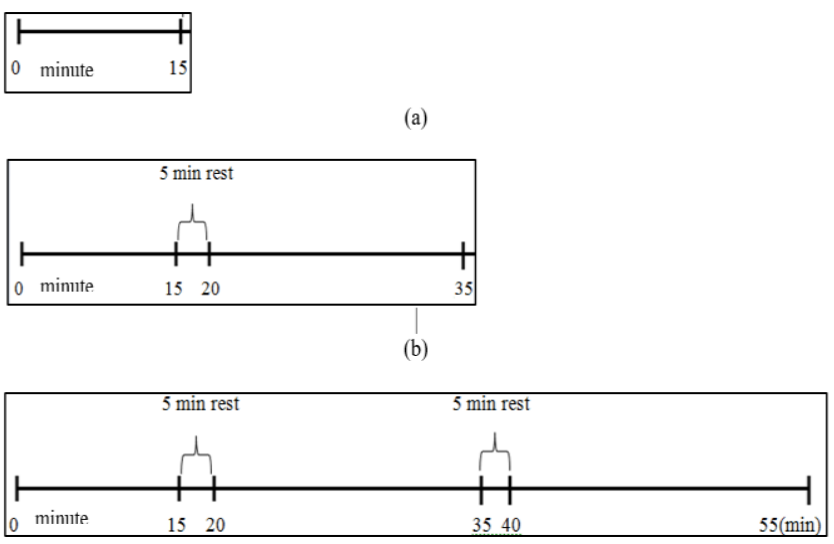

Fig. 2: Riding time for (a) day 1 (b) day 2 and (c) day 3.

\subsection{Measurement}

Muscle activity for FCR were recorded by using multichannel telemetry system EMG device (model- m 320RX, 5VDC/1A/5W, myon AG Switzerland) [12][3]. The EMG signals were filtered within bandwidth of $10 \mathrm{~Hz}-400 \mathrm{~Hz}$ and at sampling frequency of $2000 \mathrm{~Hz}$. The Disposable Ag-Cl surface electrodes (Meditrace) were placed longitudinally along the supposed direction of the muscle fi $\neg$ bers at the middle of muscle belly. The location of FCR were determined by referring to [13]. The inter-electrode distance was $2 \mathrm{~cm}$ in a bipolar configuration. The participants' skin surface was cleaned with a disposable wipe saturated with isopropyl alcohol prior to attachment of the electrodes. The EMG raw data were imported, synchronised, and analysed using ProEMG software. The mean EMG were determined and normalized with respect to the MVC. The mean value percentage of MVC was determined as:
\%MVC $=\frac{\text { Mean } E M G_{\text {exp }}}{\text { Mean } E M G_{M V C}} \times 100 \%$

\section{Results and Discussions}

\subsection{Results}

The right hand FCR (RFCR) muscle activity result for right throttle (accelerator) gripping for both RH and LH were shown in figures below (Fig. 3 and Fig. 4).

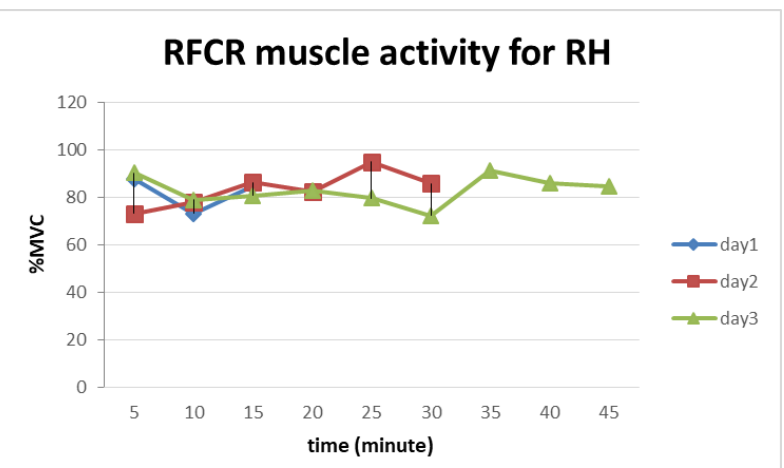

Fig. 3: Muscle activity of right handed (RH) participants when gripping right throttle.

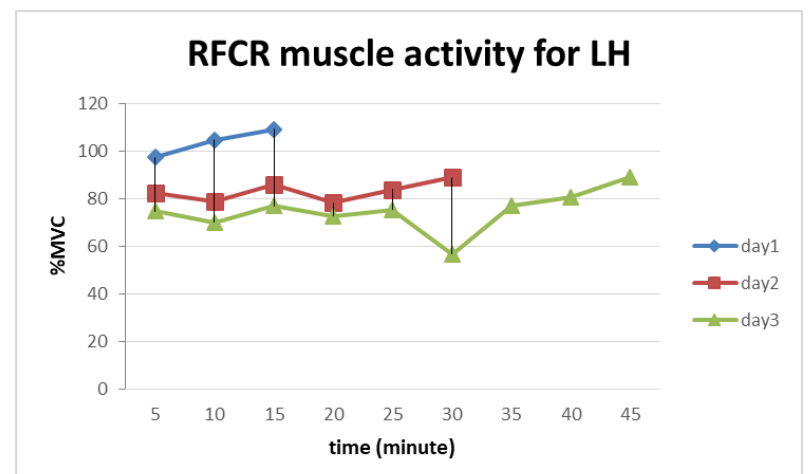

Fig. 4: Muscle activity of left handed (LH) participants when gripping right throttle.

\subsection{Discussions}

The effects of hand dominance human while using products that is designed to fit dominant hands user remains unclear even though some studies had addressed this issue. Left-handers have risk factors for accidents at work in various areas, as evidenced by the fact that the frequency of accidents among left-handers is reported to be higher than that of right-handers [14]. By referring Fig. 3 and Fig. 4, it was found that $\mathrm{LH}$ participant muscle activity was slightly higher than RH participant in gripping the right (accelerator) throttle for day 1 in particular during the first 15 minutes of riding task. The muscle activity during the first 5 minutes $(\%$ MVC) obtained from LH (non-dominant) participants is $97.4 \%$ as compared to $87.7 \%$ obtained from RH (dominant) participants respectively. During braking at corner, participant release the throttle controlling the handle to prevent from fall. To stabilize the simulation, LH participant exert more effort in releasing the grip to decreasing the speed hence the higher \%MVC than the dominant participants. Since there was no similar study to discuss on this finding, the author could only discuss on the pattern of muscle activity, where left hand muscle activity is higher during task using non-dominant hand. For instance, study by [9] showed that in the writing activity, $\mathrm{LH}$ participants flexed the wrist more than $\mathrm{RH}$. In addition, he observed that Flexor Carpi Ulnaris (FCU), FCR and Upper Trapezius (UT) were higher among LH than RH. 
However, LH participants showed lower \%MVC (74.8\% during 5 minutes riding to $77.1 \%$ during 15 minutes riding) than $\mathrm{RH}$ participants $(90.3 \%$ during 5 minutes riding to $80.7 \%$ during 15 minutes riding) in day 3 which could be caused by adaptation of the task. Meanwhile during 15 minutes rides, muscle activity was $109.13 \%$ for the LH participants as compared to $84.64 \%$ in $\mathrm{RH}$ participants. The excessive muscle activity (more than $100 \% \mathrm{MVC}$ ) could show that fatigue may have occur when riding time is longer (15 minutes as compared to 5 minutes). In addition, both LH and RH participants showed fluctuation trend of muscle activity in day 3 , which could also be a sign of muscle fatigue $[15,16]$.

\section{Conclusion}

During the riding of the simulator, higher muscle activity was shown in RFCR for LH person. This can concluded that while riding a motorcycle, non-dominant hand person needs put more effort to perform the task using dominant hand. LH participants need to activate more muscle during accelerate and brake using right hand. Objective of this study was achieved where there is different muscle activity between $\mathrm{LH}$ and RH person. Furthermore, symptom of fatigue could also been observed in day 3 even though this factor is not been critically discussed in this study.

\section{Acknowledgement}

The authors would like to thank all volunteers that participated in this study and to the Ministry of Education (MOE) Malaysia and Universiti Teknologi MARA Malaysia for providing the research fund for this study through the Geran Lestari Khas (600RMI/MyRA 5/3/LESTARI (002/2017)). The authors would also like to express their utmost gratitude to METAL for providing the experiment set up. Last but not least, special thank you to Shaiful Fahmi and Aliff Fadhullah for their assistance in conducting the experiment.

\section{References}

[1] M. M. A. Manan, A. Várhelyi, Motorcycle fatalities in Malaysia. IATSS research 36(1) (2012) 30-39.

[2] H. Rashid, M. I. N. Ma'Arof, R. Haron, W. M. S. W. Fauzi, A. R. Omar, R. Jaafar, Selection of muscle groups for surface electromyography (sEMG) measurement in analyzing motorcycling activity. Jurnal Teknologi, 76(7) (2015)103-107

[3] W. M. S. B. W. Fauzi, A. R. B. Omar, H. Rashid, H. Enhancement of Postura Motergo ${ }^{\mathrm{TM}}$ : From an ergonomic motorcycle test rig to a full-scale simulator. Journal of Mechanical Engineering (2017) 43 59.

[4] M.FM. Talib, M. I.N. Ma'Arof, H. Rashid, I.N. Ahmad, W. M. S. B W. Fauzi, R. Jaafar, The explorations in defining motorcycling fatigue: A pilot study. Jurnal Teknologi 76(7) (2015) 115-118.

[5] F. Abdullah, W. Hasrulnizzam, W. Mahmood, S.R. Kamat, S. F Afandi, M.N. Othman, Muscle activity analysis for passenger while riding moving train in prolonged standing: A case study. (May) (2018) 1-2.

[6] S.Tan, D. Lim, W. Xie, K. Liao, (2011). A study of muscle fatigue for prolonged standing using surface electromyogram: a Case Study. Portuguese Journal of Sport Sciences (2011) 775-778.

[7] Halim, A.R. Omar, A. R., A.M. Saman, I. Othman, Assessment of Muscle Fatigue Associated with Prolonged Standing in the Workplace. Safety and Health at Work, 3(1) (2012) 31-42.

[8] H. Rashid, M.I.N Ma'arof, A.R. Omar, S.C. Abdullah, I. N. Ahmad, S.A. Karim, Muscle fatigue index: An effort to help reduce motorcycle accidents. Proceedings of the international conference on $\mathrm{Er}$ gonomics \& Human Factors 2014 (2014) 425-432.

[9] S. Park, Comparison of muscle activation during dominant hand wrist flexion when writing Journal of physical therapy science, 25(12) (2013) 1529-1531.

[10] F. Kerber, M. Puhl, A. Kruger, User-independent real-time hand gesture recognition based on surface electromyography, Proceedings of the 19th International Conference on Human-Computer Interaction with Mobile Devices and Services (2017), 36.
[11] R. C. Oldfield, The assessment and analysis of handedness: The Edinburgh inventory. Neuropsychologia 9(1) (1971) 97-113.

[12] Hazari, M. Warsi, I. Agouris, Electromyography analysis of shoulder and wrist muscles in semi-professional cricket fast bowlers during bouncer and yorker delivery: A cross-sectional comparative study. International Journal of Physical Education, Sports and Health 3(6) (2016) 77-87.

[13] A.O. Perotto, Anatomical guide for the electromyographer: the limbs and trunk, third ed., Charles C Thomas, Illinois, 1994.

[14] H.S. Lee, Effects of pain input from friction on upper limb proprioception of work participants. J KSOT 19 (2011) 13-24.

[15] M. Halvorsen, D. Falla, L. Gizzi, K. Harms-Ringdahl, A. Peolsson,

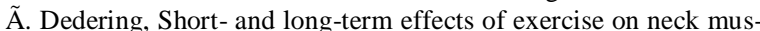
cle function in cervical radiculopathy: A randomized clinical trial. Journal of Rehabilitation Medicine, 48(8) (2016) 696-704.

[16] M. Gazzoni, A. Botter, T. M. M. Vieira, Surface EMG and muscle fatigue: multi- channel approaches to the study of myoelectric manifestations of muscle fatigue. Physiological Measurement, 38 (2017) 27-60. 